\title{
NARRATIVA INTERATIVA E PSICANÁLISE ${ }^{1}$
}

\author{
Tania Mara Marques Granato* \\ Elisa Corbett ${ }^{\#}$ \\ Tânia Maria José Aiello-Vaisberg"
}

\begin{abstract}
RESUMO. Desde sua origem a Psicanálise tem se ocupado das narrativas de pacientes que tecem suas vidas em histórias, reconhecendo nesse gênero expressivo da dramática humana a fonte de suas investigações. Além disso, os psicanalistas têm feito uso de narrativas transferenciais a fim de comunicar suas experiências clínicas à comunidade científica, contribuindo para a produção de conhecimento nessa área. A afinidade orgânica que une o narrar ao viver autoriza-nos a conceber a narrativa como modalidade de elaboração afetivoemocional do vivido. Seguindo o percurso que nos conduz da narrativa do paciente à narrativa do clínico, chegamos às narrativas interativas como proposta metodológica que retoma o narrar em seu potencial heurístico e restitui a interlocução como locus da produção de conhecimento em ciências humanas. A título de ilustração, apresentamos uma das narrativas interativas criadas como convite à elaboração de um conflito materno, seguida da narrativa de um dos participantes de um grupo-piloto.
\end{abstract}

Palavras-chave: Narrativa; psicanálise; maternidade.

\section{INTERACTIVE NARRATIVE AND PSYCHOANALYSIS}

\begin{abstract}
Since its beginning Psychoanalysis works with patients' narratives, who weave their lives into stories, recognizing in this expressive genre of the human drama as the source of its investigations. Furthermore, the psychoanalysts also elaborate transferencial narratives in order to communicate their clinical experiences to the scientific community, contributing to the production of knowledge in that field. The organic relationship that unites narration to living authorizes us to conceive the narrative as a means to elaborate affective-emotional experiences. Following the route that leads us from the patient's narrative to the psychoanalyst's narrative, we arrive to interactive narratives as a methodological procedure that rescues the heuristic potentiality of storytelling, and restore the interlocution as the locus of knowledge construction in Human Sciences. By way of illustration we present one of the interactive narratives created as an invitation to elaborate a maternal conflict, followed by a participant's narrative of our pilot sample.
\end{abstract}

Key words: Narrative; psychoanalysis; motherhood.

\section{NARRATIVA INTERACTIVA Y PSICOANÁLISIS}

RESUMEN. Desde su origen, la Psicoanálisis se ocupa de las narrativas de pacientes que tejieran sus vidas como historias, reconociendo en ese género expresivo de la dramática humana, la fuente de sus investigaciones. Los psicoanalistas han empleado narrativas transferenciales para comunicar sus experiencias clínicas a la comunidad científica, contribuyendo para producir conocimiento. La afinidad orgánica que une el narrar al vivir, autorízanos a concebir la narrativa como modalidad de elaboración afectivo-emocional del vivido. Al seguir el camino que nos lleva de la narrativa del paciente a la del clínico, llegamos a las narrativas interactivas como proposición metodológica que retoma el narrar en su potencial heurístico y

\footnotetext{
Apoio: Fapesp.

Doutora em Psicologia Clínica pelo Instituto de Psicologia da Universidade de São Paulo. Professora e orientadora do Programa de Pós-graduação da Pontifícia Universidade Católica de Campinas, Brasil.

\# Doutoranda em Psicologia pela Pontifícia Universidade Católica de Campinas, Brasil.

Il Doutora em Psicologia Clínica pelo Instituto de Psicologia da Universidade de São Paulo. Professora Livre Docente Aposentada da Universidade de São Paulo. Professora e orientadora do Programa de Pós-graduação da Pontifícia Universidade Católica de Campinas, Brasil.
} 
restituye la interlocución como locus de la producción del conocimiento en las ciencias humanas Como ilustración, presentamos una de las narrativas interactivas creadas como invitación a la elaboración de un conflicto materno, seguida de la narrativa de uno de los participantes de un grupo-piloto.

Palabras-clave: Narrativa; psicoanálisis; maternidad.

\section{DA NARRATIVA DO PACIENTE À NARRATIVA DO PSICANALISTA}

Talvez Anna O. tenha sido a primeira pessoa a reconhecer o valor terapêutico da narrativa, quando, por ocasião de suas consultas com Freud, referiu-se à "cura pela fala", sublinhando os benefícios que obtivera ao narrar o próprio drama. Em "A Interpretação dos Sonhos", obra que inaugura a Psicanálise e estrutura do método psicanalítico, Freud parte da narrativa do sonho, produzida em campo associativo, e "regula" o foco da atenção psicanalítica, a fím de ampliar a capacidade de compreender as comunicações inconscientes do sonhador. Desde os primórdios da Psicanálise, terapeutas e pacientes trabalhariam juntos, reconstruindo uma experiência pessoal que se perdera no tempo, restabelecendo conexões de sentido entre fatos psicológicos e desvendando sintomas de sofrimento psíquico.

Quando Politzer (1928/1975) se debruçou sobre a teoria psicanalítica, com o intuito de verificar as possibilidades desta como ciência psicológica, deparou-se com o que ele denominou de "a inspiração fundamental da Psicanálise" (p. 77), segundo a qual se investigariam os sentidos da conduta humana a partir do drama vivido pelo indivíduo. Distanciando-se de abstrações e de reducionismos, a Psicanálise teria recuperado, com seu procedimento narrativo, a qualidade científica que faltava à Psicologia da época. Focalizando a dramática humana, valor sempre sublinhado por Bleger (1963/1989), a Psicanálise viria a se firmar como perspectiva metodológica que investiga o sentido afetivo-emocional das condutas, diferenciando-se tanto do olhar comportamental da corrente behaviorista, cuja revitalização hoje observamos, quanto da teorização estéril, marca da Psicologia clássica, mas ainda presente nos escritos metapsicológicos freudianos, segundo o próprio Politzer.

Desde uma vertente não psicanalítica, Benjamin (1936/1992) é outro autor que ilumina a questão da narrativa, que se constitui como oportunidade de vivermos uma experiência pelas mãos do habilidoso narrador que, ao revisitar o passado, tece no presente histórias que nos remetem a um devir, garantindo assim a continuidade da humanidade no homem. Em suas preocupações com a preservação do tempo humano, aquele que outrora fora marcado pelo trabalho manual e pela transmissão oral da experiência humana, Benjamin expressava uma profunda desconfiança em relação à industrialização como mundo em que o homem pudesse manter sua humanidade. Sua argumentação segue no sentido de nos lembrar que a cópia não pertence à ordem do vivido, portanto, para que uma experiência tenha lugar, é preciso que ela se desdobre no tempo, uma vez que é processo, e não instante. Uma narrativa que se produz no tempo e de maneira espontânea é sempre singular e coletiva, pois a cada nova versão encontramos a pessoalidade do narrador assim como o contexto do qual ele parte, forjando o narrar como recurso inesgotável de comunicação do humano.

Em função dessa constante referência à experiência vivida e de seu desdobramento no tempo, as narrativas têm sido foco da atenção de autores de diversas orientações teóricometodológicas (Calvasina, Nations, Jorge, \& Sampaio, 2007; Campos \& Cury, 2009; Dutra, 2002; Melleiro \& Gualda, 2004; Rocha-Coutinho, 2005), além de se oferecerem como objeto de estudo e/ou procedimento metodológico a pesquisadores oriundos de distintas áreas do conhecimento como a Linguística, a Literatura, a Antropologia, a Filosofia e, naturalmente, a Psicanálise. Ricoeur (1999b) é um dos teóricos mais profícuos em termos de articulação entre narrativa, tempo e identidade, tendo inspirado pesquisas qualitativas (Ameigeiras, 2009; Campos \& Furtado, 2008; Dreyer \& Pedersen, 2008; Miller, 2000; Ribeiro \& Lyra, 2008; Silva \& Trentini, 2002) que fazem uso de narrativas como documento e testemunho (Ricoeur, 1999a), sublinhando o potencial elaborativo do narrar em termos de sua atribuição de sentido para a vida (Ricoeur, 1999b).

É aqui que migramos de uma concepção de narrativa como procedimento que permite ao psicanalista tanto o acesso à experiência emocional como a sua comunicação, para o reconhecimento de que o próprio narrar se constitui como processo de 
elaboração do viver. Seja organizando ou planejando, seja dando um sentido às experiências, como defendem os terapeutas narrativos, é fato que o narrar existe como atividade humana espontânea, desde que se instaure um ambiente propício à sua consecução.

A atividade de contar tem lugar quando nos deparamos com o outro nessa condição de acolhimento interessado que a Psicanálise soube aproveitar tão bem: o paciente se revelando ao terapeuta, que o recebe com o intuito de compreendê-lo, quando num determinado momento as posições se invertem e o paciente escuta as histórias que o analista constrói a seu respeito, instaurando-se o jogo do diálogo. Paciente e psicanalista jogam de acordo com as regras da Psicanálise, em um eterno movimento de construção e reconstrução de histórias que fundamentem ou legitimem o sofrimento daquele que procura ajuda profissional. Novas narrativas são assim tecidas sobre o pano de fundo das histórias de vida de ambos e dos fundamentos teóricos que iluminam aquela prática, o que se supõe que abra novas possibilidades para o ser e o viver.

Ainda no âmbito da Psicanálise, narrativas são produzidas com a finalidade de registrar o que se passou no espaço da clínica psicanalítica. Um psicanalista em cuja concepção os segredos da psique estejam gravados em cada curva do diálogo com seu paciente, preocupar-se-á em fazer anotações exaustivas, ou, quem sabe, fazer uso de um gravador, imaginando precaver-se contra as armadilhas de seu próprio inconsciente. Outro profissional, mais interessado nas flutuações transferenciais e contratransferências, registrará o processo em termos de suas alterações de rota, enquanto um terceiro analista optaria pelo modo particular com que foi impressionado pelo paciente, seja esse modo uma frase, uma música, um desenho ou uma história. Uma de nós propôs o termo narrativas transferenciais (Aiello-Vaisberg, Machado, Ayouch, Caron, \& Beaune, 2009) para esse registro que se produz em campo associativo por um psicanalista que "sonha" o encontro analítico para relatá-lo, em uma reconstrução do encontro que não visa ao retrato fiel do ocorrido, mas à revelação do vivido:

Nós nos basearemos, portanto, nesta última concepção do sonho como expressão do drama existencial durante o sono, e do relato dos sonhos como inscrição da continuidade do ser, sempre existencial, do sonhador.
Conceberemos a narrativa do acontecer clínico à luz desta atividade conhecida de todos nós, o relato dos sonhos. (AielloVaisberg et al., 2009, p. 50)

\section{A ESCRITA PSICANALÍTICA}

À semelhança do historiador de Ricoeur (1999a), o psicanalista parte de uma fase documental em direção à compreensão de seu paciente para atingir sua fase literária, dando origem ao texto psicanalítico, gênero que articula clínica e teoria. Em termos da produção escrita da Psicanálise, Ogden (2005a) entrevê como solução para a impossibilidade de se contar ou escrever um encontro analítico, que o vivido seja transformado em ficção, isto é, em uma elaboração imaginativa da experiência clínica.

\begin{abstract}
A escrita analítica é um gênero literário que conjuga uma interpretação a um trabalho artístico. Eu imagino essa forma de escrita como uma conversa entre uma idéia analítica original (desenvolvida de modo acadêmico) e a criação em palavras de algo que se assemelhe a uma experiência analítica (Ogden, 2005a, p.109)
\end{abstract}

De acordo com a concepção de Ogden (2005a), o analista-escritor não relata, antes cria uma experiência para o leitor, para quem o encontro narrado só é tornado real através dos personagens e da trama psicanaliticamente criados. Este procedimento paradoxal permite o acesso do leitor à realidade do vivido pela via da ficção, porém é único quando pretendemos comunicar o impacto emocional vivido no encontro analítico. Tomada como produto de um estado de rêverie do analista (Ogden, 2005b) aliado aos seus esforços literários, a escrita psicanalítica veicula o fato psicológico, no sentido politzeriano do termo, por meio da profunda relação que se estabelece entre a experiência vivida e a vida que emerge da narrativa.

Opondo-se à concepção freudiana do analista como arqueólogo da mente que explora as memórias de seu paciente em busca de relíquias do passado, Spence (2003) é outro autor que defende que a elaboração literária do psicanalista se dá naquele mesmo estado de tolerância à dúvida, à incerteza e ao mistério, no qual ele se propõe escutar seu paciente. Como Ogden (2005a), Spence também concebe a narrativa psicanalítica como a única evidência que temos do encontro analítico, cujas nuanças emocionais são comunicadas através dos recursos literários, dos 
quais se serve o analista na construção de seu testemunho.

É nesse ponto que as elaborações anteriores de Spence sobre uma verdade narrativa em oposição à verdade histórica dão lugar ao que ele passou a designar de verdade retórica (Spence, 2003) - aquela que é comunicada pelo estilo de uma narrativa e se inspira nos grandes autores da literatura e em suas habilidades para comunicar estados emocionais. A chamada de Spence (2001) a que nos voltemos para a literatura origina-se de sua observação sobre a necessidade de que as vozes de nossos pacientes sejam incluídas nos textos psicanalíticos, lamentavelmente recheados de teoria e vazios de vida. Essa possibilidade é apontada por Ogden (2001) quando se refere à singularidade da escrita de Winnicott, que lhe parece convidar o leitor a viver, através de textos curtos, de uma linguagem viva e mais próxima da experiência, da escolha de palavras e sons, da abundância de verbos e da relativa escassez de relatos clínicos, a experiência de ser compreendido e, assim, incluído na experiência humana comum.

Griffin (2005) é outro psicanalista que fez uso da literatura, desta vez para superar um impasse terapêutico. Ansioso por compreender um determinado paciente que lhe sinalizava a possibilidade de suicídio, Griffin sentiu-se invadido pela necessidade de interpretá-lo, na esperança de evitar o suicídio anunciado, o que provocou o repúdio do paciente a toda e qualquer interpretação que apresentasse. Tomado pelo impasse, Griffin lembrouse de uma short story, na qual eram narrados os vãos esforços de um médico para examinar uma criança com suspeita de difteria que se recusava a cooperar, cerrando a boca e impedindo o exame clínico.

Segundo Griffin (2005), a releitura daquela história promoveu o restabelecimento do espaço imaginativo que lhe permitiu compreender as reais necessidades de seu paciente, renunciando à urgência interpretativa que dele se apoderou. Griffin conclui o relato dessa experiência clínica atribuindo o efeito mutativo de um texto literário à maneira singular com que seu autor formula uma determinada experiência emocional, produzindo ecos na experiência do leitor, em um processo bastante semelhante ao que ocorre no encontro analítico.

Nossa experiência clínica com gestantes e mães da Ser e Criar (Atendimento Psicológico na Gestação e Pós-parto), em contexto acadêmico de pesquisaintervenção (Aiello-Vaisberg \& Granato, 2006; Granato, 2006; Granato \& Aiello-Vaisberg, 2008; 2009), possibilitou-nos não apenas formular uma clínica winnicottiana da maternidade, mas também colher uma rica documentação narrativa sobre a experiência emocional materna. Inspiradas pelas conquistas e impasses da maternidade, lembramo-nos de como foi particularmente tocante o apelo de uma de nossas pacientes que, em meio ao sofrimento da perda de seu filho, procurava conforto na literatura religiosa: "Eu leio, acho lindas as histórias, mas nenhuma é exatamente o que aconteceu comigo, eu queria ler a minha história!’"

\section{NARRATIVAS INTERATIVAS}

Já dissemos que o narrar, antes de ser tomado por psicanalistas, linguistas, antropólogos e outros pesquisadores como ferramenta básica de seu ofício, era a forma original pela qual as pessoas compartilhavam suas experiências, aprendiam com os antepassados e orientavam as novas gerações segundo linhas de conduta moral e ética. Tal narrar tinha, assim, uma função prática, transmitindo notícias, conselhos, advertências, ofícios - enfim, experiências de vida. O psicanalista é um profissional que recupera a narrativa humana como meio fidedigno de acesso ao mundo pessoal, revelando-se poderoso recurso na produção de conhecimento sobre a experiência afetivo-emocional.

A proposta de uso de narrativas interativas na pesquisa psicológica vem ao encontro de anseios de disponibilizar recursos e conhecimentos psicanalíticos em contextos onde a análise-padrão seria inviável ou considerada inapropriada. Assim é o caso da pesquisa psicanalítica, das psicoterapias breves, dos grupos de trabalho, de pacientes de baixo poder aquisitivo, do trabalho institucional, ou ainda do tratamento de pacientes que demandam uma abordagem psicanalítica diferenciada (Winnicott, 1962/ 2003).

Numa investigação psicanalítica como a que propomos não poderíamos nos furtar ao desafio de criar um procedimento que fizesse jus ao potencial elaborativo do narrar e preservasse maximamente a característica dialógica do encontro humano. Assim chegamos às narrativas interativas, procedimento que privilegia a interlocução entre pesquisador e pesquisado na produção de um conhecimento que se assente sobre a dramática humana.

Em virtude de nossa linha clínico-investigativa na área da maternidade, optamos por criar uma história fictícia que comunicasse um drama materno. Entretanto, como bem o dizia Lhosa (2006), para que uma história tenha a força de mobilizar emocionalmente o leitor ela precisa guardar forte relação com a vida e seus desafios. Para tal empreitada contamos com nossa experiência pessoal e 
profissional, alicerçando esta investigação no campo da intersubjetividade.

A título de ilustração do recurso metodológico aqui proposto apresentamos, logo abaixo, uma das narrativas interativas elaboradas de modo a envolver emocionalmente o leitor, permitindo-lhe que dê continuidade a essa história, que a certa altura se interrompe, como convite a que ele dela se aproprie e que faça uso imaginativo do campo de sentidos afetivo-emocionais que apresenta.

Dona Mercedes sabia que boa coisa não era, quando a filha chegava assim de mansinho para falar com ela. Nunca aprovou a amizade de Aninha com o filho da patroa que, apesar de bom menino, era como a maioria dos adolescentes ricos - mimado e irresponsável. Aninha deu mil voltas antes de contar à mãe que estava grávida, temia que ela ficasse furiosa e não lhe desse o apoio de que tanto precisava. Nem bem teve tempo de pensar sobre a revelação da filha, D. Mercedes foi procurada pela patroa que, descontrolada como de costume, gritava ao telefone:

— Mercedes! Você viu o que a sua filha fez com meu filho?! Ela deve ter embebedado o pobrezinho! Ela vai tirar, não vai? Fique tranquila, eu pago todas as despesas. O que não dá é pra ser pai aos 17 anos, né?

- Alto lá, Dona Leila! Minha filha não é de enganar e nem mentirosa, se ela perdeu o juízo foi em companhia do seu filhinho! Se ela vai abortar eu não sei, estou tentando conversar com ela...

Naquela noite, depois de muita discussão, D. Mercedes e a filha se acalmaram e puseramse a conversar. Aos 15 anos, Aninha tinha medo de abortar, medo de Deus, medo da mãe, mas também tinha medo de ser mãe. Sabia das dificuldades que a mãe teve para criá-la, depois que o pai morreu de tanto beber. Agora ela estava no Colegial e queria fazer faculdade... Danilo era um menino lindo, mas um crianção. Não dava para pai e nem para marido, pelo menos por enquanto. Com medo da dor do parto, Aninha resolveu trocar uma idéia com a vizinha que era enfermeira, mas esta lhe respondeu secamente:

—Na hora de fazer não doeu, né? Agora tá com medo?

D. Leila ofereceu dinheiro. D. Mercedes disse que ficaria ao lado da filha, aguardando sua decisão, mas deixou bem claro que não poderia largar o trabalho para cuidar do neto. Danilo aguardava o desenrolar dos acontecimentos, pois tinha medo de contar ao pai, que era uma fera! Aninha não queria um marido medroso, não tinha dinheiro, mas sempre sonhou em ter um filho. Desesperada, Aninha não sabia mais o que pensar, por um momento achou que sua vida tinha chegado ao fim, e voltar no tempo era impossível...

Optamos por apresentar essa narrativa a um pequeno grupo, sendo esta nossa primeira experiência com o uso de narrativas interativas nesse enquadre diferenciado em que o pesquisador oferece uma primeira elaboração sua - portanto, pessoal - ao pesquisado, que é solicitado a engajar-se naquele trabalho como parceiro na produção de um saber imaginativo sobre o drama de uma adolescente que engravida. Quatro participantes de um grupo de trabalho aceitaram o convite de uma de nós para que colaborassem com uma pesquisa sobre o cuidado materno, mostrando-se bastante interessados. Instigante também foi a conversa que permeou a leitura e a escrita dos participantes, atestando já de saída a produção imaginativa desencadeada pela proposta em si - atividade que se assemelha ao rabisco winnicottiano (Winnicott, 1971) de acordo com o qual o terapeuta faz um rabisco sobre uma folha de papel em branco abrindo todo um campo de possibilidades ao paciente, que o completa, na melhor das hipóteses, de forma também espontânea, portanto, genuína.

Nesse espaço lúdico, em que o brincar remete às coisas sérias da vida (Winnicott, 1971), um dos participantes - o único homem - comenta com suas colegas que a história dele seria a única "real", a única que contaria a "realidade", e não "aquelas novelas que vocês escreveram...". Tal comentário teve lugar quando as participantes ainda entregavam suas histórias à pesquisadora, e deu início a uma acalorada discussão, alimentada pela leitura em voz alta das histórias. Não era nossa intenção que as histórias dos participantes fossem reveladas aos demais integrantes do grupo, mas que fossem mantidas em sigilo pelo pesquisador, que finalizaria o procedimento, abrindo um espaço para a discussão da temática veiculada pela história. Tomando-o como necessidade dos participantes, a pesquisadora passou a intermediar a conversa que acompanhou a leitura de suas histórias.

Embora não seja objetivo deste trabalho apresentar e discutir em profundidade os resultados de nosso primeiro contato com o procedimento das narrativas interativas, gostaríamos de compartilhar com o leitor algumas observações que julgamos 
relevantes enquanto indicadoras do potencial heurístico de um proceder que, através da atividade ancestral do narrar, resgata a intersubjetividade na pesquisa. Pelo comentário do rapaz sobre as "novelas" das moças, poderíamos aventar a hipótese de que no imaginário masculino as mulheres lidam com conflitos sobre aceitação ou recusa do papel materno tingindo de "rosa" a vida cruel, na qual o aborto seria o desfecho mais provável. Já para as mulheres de nosso pequeno grupo, um final como este se mostra impraticável desde o início, restando-lhes a decisão sobre o modo como Aninha cuidará de seu filho sem sacrificar a própria vida, do que poderíamos depreender o conflito feminino contemporâneo quanto à possibilidade de conciliação da tarefa materna com a realização pessoal. Outro achado bastante expressivo das produções imaginativas em torno do cuidado materno se refere ao fato de a figura materna jamais abandonar sua prole. Mesmo no caso em que Aninha, a protagonista, decide abortar, pudemos observar que sua mãe se mantém firme no apoio que pretende oferecer à filha, seja para criar seu neto seja para descartá-lo.

Com o intuito de deixar aqui o testemunho da riqueza e diversidade das narrativas que se produzem na presença de um interlocutor interessado, atestando a fertilidade do campo interativo, reproduzimos uma das histórias que se produziram a partir de nosso "rabisco":

\begin{abstract}
"Aninha não sabia o que fazer, sem apoio e pressionada pensou que abortar seria a única solução. Tinha medo do parto e sentia uma imensa vontade de ter este filho, porem não queria ser uma mãe ruim e despreparada. Não queria abdicar do seus sonhos de continuar os estudos e assim perpetuar algo que sempre vira em casa: emprego ruim, uma mãe que não sabia ler direito, criar um filho sem a presença do pai.
\end{abstract}

Assim decidida Aninha resolveu chamar a mãe e contar a sua decisão.

- Mãe, tenho medo, mas acho que o melhor seria tirar este filho. Mas tem que ser agora que a barriga não cresceu, porque depois não teria coragem.

- Filha, a decisão é sua. Vou apoiá-la no que for preciso.

- Eu sei, mãe! Eu errei e não quero abdicar dos meus sonhos de estudar e dar uma vida melhor para mim e para a senhora.
A mãe sabia que a filha tinha estava decidida, porém no fundo ela sofria. Aninha tinha amadurecido em poucas semanas com toda esta historia. Porém a mãe entendia, pois criou a filha praticamente sozinha e por isto nunca pode pensar em estudos. Ana poderia ter um destino melhor, um destino diferente.

As duas pegaram o dinheiro dado por D. Leila e foram a um clinica indicada por ela. Elas nunca tinham entrado em um lugar assim. Aninha mesmo assustada realizou todo o procedimento. Elas retornaram para casa, caladas.

No outro dia, D. Mercedes já estava na casa de D. Leila limpando a casa como de costume. De longe Dona Leila esbaforida, começa a gritar: - Foi o melhor para todos Mercedes! Você e sua filha tomaram a decisão certa!

Mercedes ouve e suspira antes de responder:

Foi o melhor para minha filha e seu futuro! Não quero que ela sofra como eu sofri!"

\section{REFERÊNCIAS}

Aiello-Vaisberg, T. M. J., \& Granato, T. M. M. (2006). Ser e Fazer na clínica winnicottiana da maternidade. Aparecida, SP: Ideias e Letras.

Aiello-Vaisberg, T. M. J., Machado, M. C. L., Ayouch T., Caron R., $\&$ Beaune, D. (2009). Les récits transférenciels comme presentation du vécu clinique: une proposition méthodologique. In D. Beaune (Org.). Psychanalyse, Philosophie, Art: Dialogues (pp. 39-52). Lille: L'Harmattan.

Ameigeiras, A. (2009). L'herméneutique dans l'approche ethnographique. Du labyrinthe de la compréhension au défi de l'interprétation. Recherches Qualitatives, 28(1), 37-52.

Benjamin, W. (1992). O Narrador: reflexões sobre a obra de Nikolai Leskov. In W. Benjamin, Sobre Arte, Técnica, Linguagem e Política (pp. 27-57). Lisboa: Relógio D’Água. (Original publicado em 1936).

Bleger, J. (1989). Psicologia da Conduta. Porto Alegre: Artes Médicas. (Original publicado em 1963).

Calvasina, P. G., Nations, M. K., Jorge, M. S. B., \& Sampaio, H. A. C. (2007). "Fraqueza de Nascença": sentidos e significados culturais de impressões maternas na saúde infantil no Nordeste brasileiro. Caderno de Saúde Pública, 23(2), 371-380.

Campos, A. P. S., \& Cury, V. E. (2009) Atenção psicológica clínica: encontros terapêuticos com crianças em uma creche. Paidéia, 42(19), 115-121.

Campos, R. T. O., \& Furtado, J. P. (2008). Narrativas: utilização na pesquisa qualitativa em saúde. Revista de Saúde Pública, 42(6), 1090-1096. 
Dreyer, P. S., \& Pedersen, B. D. (2008). Distanciation in Ricoeur's theory of interpretation: narrations in a study of life experiences of living with chronic illness and home mechanical ventilation. Nursing Inquiry, 16(1), 64-73.

Dutra, E. (2002). A Narrativa como técnica de pesquisa fenomenológica. Estudos de Psicologia (Natal), 7(2), 371-378.

Granato, T. M. M. (2006). Modelo de Pesquisa em Psicologia da Saúde. In F. Bortoletti (org.), Psicologia na Prática Obstétrica: abordagem interdisciplinar (pp. 141-150). São Paulo: Ed. Manole.

Granato, T. M. M., \& Aiello-Vaisberg, T. M. J. (2008). I was looking for a different treatment. Psychoanalytic Review, 95(4), 655- 667.

Granato, T. M. M., \& Aiello-Vaisberg, T. M. J. (2009). Maternidade e colapso: consultas terapêuticas na gestação e pós-parto. Paideia, 19(44), 395-401.

Griffin, F. L. (2005). Clinical Conversations between Psychoanalysis and Imaginative Literature. Psychoanalytic Quarterly, 74(2), 443463.

Lhosa, M. V. (2006). Cartas a um Jovem Escritor. Rio de Janeiro: Elsevier.

Melleiro, M. M., \& Gualda, D. M. R. (2004). Experiências e Expressões de Gestantes na Interação com o Sistema de Saúde: um enfoque fotoetnográfico. Revista Latino-americana de Enfermagem, 12(3), 503-510.

Miller, T. (2000). Losing the Plot: Narrative Construction and Longitudinal Childbirth Research. Qualitative Health Research, 10(3), 309-323.

Ogden, T. H. (2005b). This Art of Psychoanalysis: dreaming undreamt dreams and interrupted cries. In T. H. Ogden, This Art of Psychoanalysis: dreaming undreamt dreams and interrupted cries (pp. 1-18). London: Routledge.

Ogden, T. H. (2001). Reading Winnicott. Psychoanalytic Quarterly, 70(2), 299-323.

Ogden, T. H. (2005a). On psychoanalytic writing. In T. H. Ogden, This Art of Psychoanalysis: dreaming undreamt dreams and interrupted cries (pp. 109-123). London: Routledge.
Politzer, G. (1975). Crítica dos Fundamentos da Psicologia. Lisboa: Editorial Presença. (Original publicado em 1928).

Ribeiro, A. K., \& Lyra, M. C. D. P. (2008). O processo de significação no tempo narrativo: uma proposta metodológica. Estudos de Psicologia (Natal), 13 (1), 65-73.

Ricoeur, P. (1999a). Humanities between Science and Art. Universidade de Arhus, Dinamarca. Recuperado em 22 junho, 2009, http://www.hum.au.dk/ckulturf/pages/publications/pr/hbsa.htm.

Ricoeur, P. (1999b). Historia y Narratividad. Barcelona: Paidós Ibérica. (Original publicado em 1978).

Rocha-Coutinho, M. L. (2005). A narrativa oral, a análise de discurso e os estudos de gênero. Estudos de Psicologia (Natal), 11(1), 6569.

Silva, D. G. V., \& Trentini, M. (2002). Narrativas como Técnica de Pesquisa em Enfermagem. Revista Latino-americana de Enfermagem, 10(3), 423-432.

Spence, D. P. (2001). Case Reports in a Two-Person World. Psychonalytic Psychology, 18(3), 451-467.

Spence, D. P. (2003). Listening for rethorical truth. Psychoanalytic Quarterly, 72(4), 875-903.

Winnicott, D. W. (1971). Therapeutic Consultations in Child Psychiatry. New York: Basic Books.

Winnicott, D. W. (2003). The Aims of Psycho-Analytical Treatment. In D. W. Winnicott. The Maturational Processes and the Facilitating Environment (pp. 166-170). London: Karnac. (Original publicado em 1962).
Endereço para correspondência:
Tania Mara Marques Granato. Rua Bernardino de Campos, 318, conj. 114, Brooklin CEP 04602-001, São Paulo- SP, Brasil. E-mail: taniagranato@uol.com.br.
Recebido em 23/04/2010

Aceito em 28/02/2011 